Jurnal Ilmu Komunikasi UHO : Jurnal Penelitian Kajian Ilmu Komunikasi dan Informasi.

Volume 6, No. 1, Januari 2021, hlm 98-111

\title{
GAYA KOMUNIKASI PENYIAR DALAM MEMPERTAHANKAN EKSISTENSI RADIO
}

\author{
Fadilla Rizky Febriyanty, ${ }^{1}$ Femi Oktavini ${ }^{2}$ \\ Universitas ARS Bandung Jawa Barat \\ Jurusan Ilmu Komunikasi, Fakultas Komunikasi dan Desain \\ Email : fadillarizky00@gmail.com \\ feoktav@ars.ac.id
}

\begin{abstract}
ABSTRAK
Dahlia merupakan radio nomor satu di Bandung yang mempunyai reputasi tinggi di antara radio lainnya, radio Dahlia lebih berfokus pada musik dangdut dangdut dan pop sunda yang menjadi trendsetter bagi pecinta musik dangdut di Kota Bandung dan sekitarnya, sehingga radio dahlia membuat program unggulannya yaitu Bandar Dangdut, suatu program radio tidak terlepas dari seorang penyiar yang biasa mencairkan suasana agar para pendengarnya menjadi antusias untuk mendengarkan program mereka, oleh karena itu kemapuan komunikasi yang baik harus di miliki seorang penyir, tujuan dari penelitian ini untuk mengetahui penyiar bandar dangdut dalam mempertahankan ekstitensi radio Dahlia, penelitian ini juga menggunakan metode kualitatif dengan pengambilan data menngunakan wawancara, obrsevasi, dan dokmuntasi, teori yang di gunakan yaitu logika pesan. Hasil dari penelitian ini yaitu terdiri dari faktor-faktor logika pesan yaitu, Logika ekspresif, Logika konvensional dan Logika retorika. Proses komunikasi massa yang dilakukan penyiar radio Dahlia mampu menarik minat para pendengarnya, dengan ciri khasnya yang selalu menggunakan gaya nge-rap saat membawakan program acaranya, ini yang menjadikan radio Dhalia menjadi nomor satu dan terdepan di Kota Bandung.
\end{abstract}

Kata-kata Kunci: Gaya Komunikasi, Komunikasi massa, Logi pesan, Radio 
Jurnal Ilmu Komunikasi UHO : Jurnal Penelitian Kajian Ilmu Komunikasi dan Informasi.

Volume 6, No. 1, Januari 2021, hlm 98-111

\title{
BROADCASTER COMMUNICATION METHOD IN MAINTAINING RADIO EXSISTENCE
}

\begin{abstract}
Dahlia is the number one radio in Bandung that has a high reputation among other radios, Dahlia radio is more focus on Dangdut dangdut music and pop Sundanese that become a trendsetter for dangdut music lovers in the city of Bandung and its surroundings, so that the radio Dahlia made its flagship program, the Bandar Dangdut, a radio program is not separated from a broadcaster who commonly melt the atmosphere so that the listeners become enthusiastic to listen to their programs, therefore good communication needs to be in possession of a banker, the purpose of this research to know Dangdut City broadcasters in maintaining the radio extension Dahlia, this research also uses qualitative methods with data retrieval using interviews, sale, and Dokmuntasi, the theory in use that is logic message. The results of this research are composed of the message logic factors namely, expressive logic, conventional logic and rhetoric logic. The process of mass communication conducted by radio broadcaster Dahlia was able to attract the interest of his listeners, with his trademark that always used the style of nge-rap when carrying the program, this which makes Dhalia radio become the number one and the leading in the city of Bandung.
\end{abstract}

Keywords: Communication style, Mass communication, message Logi, Radio 
Jurnal Ilmu Komunikasi UHO : Jurnal Penelitian Kajian Ilmu Komunikasi dan Informasi.

Volume 6, No. 1, Januari 2021, hlm 98-111

\section{PENDAHULUAN}

Manusia adalah mahluk sosial yang tidak akan pernah lepas dari interaksi dan komunikasi antar sesamanya oleh karena itu komunikasi sangat lah penting untuk menunjang kehidupan kita sehari-hari, kita sebagai mahluk sosial dimanapun dan kapanpun peran komunikasi sangat lah penting dengan berbagai aktivitas masing-masing. Melalui komunikasi dapat mempermudah kita untuk bergaul sehingga kita dapat saling mengenal, memahami dan menerima satu sama lain, dengan proses komunikasi juga kita dapat berbagi pengetahuan dan pengalaman, serta kita dapat memperluas relasi dan meminimalisir terjadinya konflik dalam bermasyarakat.

Komunikasi dapat menimbulkan konflik dengan sesamanya, karena salah pengertian (misscommunication) dalam diri kita atau pun orang lain. Konflik tersebut bisa terjadi karena kurang pemahaman dalam mengartikan sebuah pesan yang disampaikan, melalui komunikasi, kita bisa mengetahui sikap dan perasaan seseorang atau sekelompok orang, jadi kita harus lebih berempati terhadap gaya komunikasi lawan bicara, pada saat kita sedang ngobrol tentu saja kita akan memberikan respon dan menyesuaikan posisi tubuh agar terjadi kenyamanan dengan lawan bicara. Komunikasi akan lebih efektif apabila pesan yang disampaikan dapat diterima oleh penerima pesan tersebut, maka dari itu komunikasi sangat lah berperan penting untuk menunjang kehidupan bermasyarakat. Pentingnya komunikasi dalam kehidupan bermasyarakat, salah satunya meminimalisir terjadinya konflik, selain itu agar setiap orang bisa menjalani hubungan baik dengan antar masyarakat, manfaat dari komunikasi dalam kehidupan bermasyarakat sangatlah banyak, kita dapat memberi atau menerima informasi yang dapat menciptakan hal-hal baru.

Meskipun manusia sangat berbeda satu sama lainnya, berbeda dalam gaya bahasanya, gaya nada bicaranya, gaya merespons pesan yang disampaikan, dan gaya pemahamannya. Kita adalah mahluk yang paling sempurna karena diberikan akal pikiran, maka dari itu manusia selalu mengalami perubahan, karena perubahan tersebut tidak terlepas dari interaksi dan berkomunikasi. Dalam komunikasi juga ada pesan yang disampaikan secara verbal (bahasa lisan), bahas verbal adalah komunikasi menggunakan tulisan ataupun lisan, bentuknya berupa ucapan atau kata-kata, komunikasi verbal efektifnya orang yang berinteraksi mengerti bahasa yang digunakan dan kata-kata atau ucapan tersebut bisa mempengaruhi orang disekitarnya. Sedangkan secara non verbal (bahasa isyarat), bahasa non verbal tidak menggunakan bahasa secara langsung biasanya digunakan penguat komunikasi 
Jurnal Ilmu Komunikasi UHO : Jurnal Penelitian Kajian Ilmu Komunikasi dan Informasi.

Volume 6, No. 1, Januari 2021, hlm 98-111

verbal, misalnya saat kita sedang berbicara kita tidak sadar melakukan gerakan-gerakan tubuh seperti sentuhan, lambaian tangan, tujuk tangan dan isyarat-isyarat fisik lainnya.

Selain dari komunikasi kehidupan manusia tidak akan lepas dari membutuhkan informasi dan hiburan, pada saat ini teknologi komunikasi semakin canggih, bentuk pola dan peralatan komunikasi juga mengalami perubahan, komunikasi tidak dilakukan hanya personal, namun dilakukan secara berkelompok (massa). Massa yang dimaksud dalam hal ini adalah kumpulan individu yang berada disuatu lokasi tertentu, yang disebut sebagai penerima pesan atau sering disebut khalayak, audience, penonton, pemirsa dan pembaca. Dengan berkembangnya zaman, banyak media massa yang menyuguhkan informasi dan hiburan, diantaranya media cetak seperti majalah, surat kabar, dan tabloid. Dan media elektronik seperti televisi, radio, dan internet (new media). Dari media massa tersebut bukan hanya informasi yang akan didapat, kita juga bisa mendapatkan hiburan. Salah satunya alat komunikasi yang sudah sejak dari dulu banyak digunakan yaitu radio.

Membincangkan radio siaran, disadari atau tidak, siapapun tak menduga sebelumnya, radio bakalan digemari secara merakyat. Sebagai benda fisik yang lazim disebut pesawat radio, bisa didengarkan melalui gelombang atau frekuensi SW (Short Wave), AM (Amplitudo Modulation), dan FM (Frequency Modulation) berkat penemuan teknologinya dari para pakar radio tertentunya. Di dalam perkembangan zamannya ternyata medium non visual ini, bisa menjadi media massa mampu media komunikasi dalam menyampaikan beragam inforasi/berita dan hiburan (musik/lagu, drama, kuis, humor) kepada pendengar. (Tiartanto, 2010) Meskipun radio memberikan informasi lewat suara saja tetapi radio banyak peminatnya karna radio adalah salah satu media massa elektronik tertua. Radio sampai sekarang masih tetap bertahan pada era teknologi yang semakin canggih karena radio memiliki sifat-sifat yang berbeda dengan media lainnya, sebelum ada televisi dan internet. Radio sama seperti surat kabar yang berfungsi memberikan informasi, menghibur, mendidik, dan melakukan persuasi.

Radio bersifat auditif yang berarti hanya untuk didengarkan, maka dari itu penyiar lebih baik menggunakan bahasa yang sederhana, kalimat yang ringkas dan susunan kalimat yang logis dengan bergaya obrolan, karena setiap perkataan yang dikeluarkaan penyiar harus dapat di percaya, baik itu bersifat hiburan atau informasi. Berbeda dengan televisi bersifat audiovisual yang berarti dapat dilihat dan didengarkan. Alasan radio banyak diminati dan didengarkan oleh masyarakat karena radio sangat praktis, karena radio bersifat secara langsung, ketika menyampaikan suatu informasi tidak menggunakan teknik yang berbelit, 
Jurnal Ilmu Komunikasi UHO : Jurnal Penelitian Kajian Ilmu Komunikasi dan Informasi.

Volume 6, No. 1, Januari 2021, hlm 98-111

tidak mengenal jarak dan waktu, dapat didengar dimana saja dan kapan saja. Bahkan pada saat berkendara dimobil, pendengar tetap bisa mendapatkan hiburan melalu musik yang diputar oleh radio tertentu dan pendengar juga mendapatkan informasi seperti berita. Berkat kemajuan teknologi saat ini radio juga tidak hanya bisa didengarkan melalui radio tape saja, melaikan dapat didengarkan juga di handphone.

Radio menyiarkan hiburan untuk pendengarnya, salah satunya melalui program acara musik, selain itu pendengar juga dapat berinteraksi langsung dengan penyiar melalui layanan telepon atau pesan singkat. Penyiar radio (announcer) memiliki nilai seni yang tinggi karena mereka harus memahami model-model komunikasi yang dapat menyampaikan pesan secara efektif kepada pendengarnya, karena penyiar harus pintar-pintar dalam pengolahan kata, gimik yang digunakan, bahkan dengan gaya bicara yang khas yang akan mampu menghipnotis pendengarnya. Pendengar adalah orang-orang yang dapat menjadi loyal terhadap penyiar, dan bersahabat serta memiliki rasa kekeluargaan yang tinggi terhadap stasiun radio yang mereka dengarkan. Penyiar juga harus mampu mengakrabkan diri dengan pendengar sehingga akan tercipta adanya kedekatan antra penyiar dengan pendengar. Jadi, peran penyiar itu sangat lah penting untuk tetap menarik perhatian pendengarnya, agar pendengar tidak memindahkan atau mematikan channel gelombang radio tersebut.

Keberhasilan suatu radio adalah para penyiar, penyiar akan selalu berusaha dengan segala kekereatifannya untuk menghidupkan radio diantara pendengarnya. Sosok penyiar akan menjadi patokan rating sebuah stasiun radio, dan menjadi brand image, kemampuan atau kegagalannya dapat mempengaruhi citra khalayak terhadap stasiun radio dimana seorang penyiar bertugas, penyiar harus mampu menyampaikan suatu pesan informasi hanya dengan bermodalkan audio saja sedangkan pesan yang disampaikan oleh penyiar harus bisa diterima dan dipahami oleh pendengarnya dengan baik. Selain itu, penyiar bertugas untuk menghibur memberikan kesan riang dan lincah untuk membentuk kepribadian penyiar, karena secara tidak langsung kesan itu akan menular kepada pendengar, karena pendengar tidak ingin merasakan kesedihan yang sedang terjadi kepada penyiar karena tujuan mendengarkan radio itu untuk hiburan, maka dari itu seorang penyiar harus memiliki kemampuan lebih bukan hanya sekedar berbicara saja. tetapi harus memperhatikan 3 hal penting yang harus dimiliki oleh seorang penyiar, yaitu annoucing skil (keterampilan menuturkan segala sesuatu menyangkut dengan musik, kata, atau lirik lagu yang disajikan), operating skil (keterampilan mengoprasikan segala peralatan siaran), dan musical touch (keterampilan merangkai musik 
Jurnal Ilmu Komunikasi UHO : Jurnal Penelitian Kajian Ilmu Komunikasi dan Informasi.

Volume 6, No. 1, Januari 2021, hlm 98-111

dalam tatanan yang menyentuh emosi pendengar). Penggunaan gaya komunikasi pun harus sesuai dengan kebutuhan masyarakat untuk menjaga eksistensi radio tersebut.

Penyiar radio di era sekarang pun dituntut untuk menguasa multibahas agar mengikutin tuntutan pasar, dengan demikian pendengar tidak akan meninggalkan program acara yang disiarkan radio tertentu, maka dari itu gaya bahasa yang digunakan penyiar tentu saja tergantung sifat acara program radio, namun terkadang gaya bahasa yang digunakan penyiar itu lebih informal supaya lebih dekat dan akrab dengan pendengarnya, gaya bahasa yang di bawakan oleh penyiar pun sangat membantu terhadap eksisistensi acara bahkan stasiun radio. Tetapi bukan hanya dari sosok penyiar dan gaya bahasa yang digunakan saat siaran saja yang bisa mempertahankan eksistensi radio tersebut melainkan stasiun radio pun harus memiliki program unggulan yang dapat diminati oleh pendengarnya, dengan semakin banyak persaingan diantar stasiun radio lainnya radio harus banyak strategi atau ide yang bagus yang dapat diterima oleh khalayak banyak agar tetap eksis diantara radio lainnya.

Menjadi seorang penyiar ada beberapa hal yang harus dilakukan dan dicermati, penyiar harus mampu melibatkan pendengar dalam setiap program acara yang dibawakannya, gaya komunikasi yang digunakan harus mampu menjadi daya tarik, hal yang perlu dilakukan penyiar agar melibatkan pendengar dalam program acaranya harus menguasai program acara yang dibawakan, tunjukan kekuatan program dan manfaat dari menyimak program acara tersebut. Gaya komunikasi merupakan ciri khas yang dimiliki oleh seseorang, setiap orang memiliki gaya komunikasi yang berbeda-beda, dari gaya bahasa, gaya nada bicara, dan mimik muka, begitupun gaya komunikasi seorang penyiar radio.

Gaya komunikasi penyiar radio harus mampu menghidupkan pembicaraan dengan para pendengar, pendengar adalah salah satu target sasaran program acara dibuat oleh radio. Seorang penyiar harus mampu menguasai program acaranya karena agar lebih menarik dan menyedot para pendengar, gaya komunikasi seorang penyiar harus dapat mempengaruhi pesan yang terjadi antara komunikan dan komunikator sehingga komunikasi akan berjalan dengan lancar. Penyiar adalah juru bicara stasiun radio, penyiar memiliki pekerjaan dan tugas lain sesuai keterampilan yang dia miliki, dengan begitu penyiar harus akting sebagai pembawa acar atau pelawak, membawakan kuis, mewawancara, dan menyiarkan berita atau informasi, dengan begitu seorang penyiar harus lebih persuasif dan komunikatif pada pendengar. Penyiar agar tetap bisa mempertahankan program acara yang dibawakannya tetap eksis dikalangan masyarakat, penyiar harus memiliki gaya bahasa yang dapat di mengerti dan diterima oleh masyarakat, sehingga akan tercipta suasana positif bagi para pendengar. gaya 
Jurnal Ilmu Komunikasi UHO : Jurnal Penelitian Kajian Ilmu Komunikasi dan Informasi.

Volume 6, No. 1, Januari 2021, hlm 98-111

bahas merupakan kepandaian berbicara dan menulis untuk meyakinkan dan mempengaruhi bagi pendengar dan pembaca. Jadi gaya bahasa yang harus di gunakan penyiar bandar dangdut harus mengikuti trand pasar dan dapat diterima oleh khalayak luas.

Hal ini pun tidak terlepas dari model komunikasi, karena model komunikasi pada saat siaran pun harus terarah, sebagai seorang penyiar harus bisa menepatkan model komunikasi yang tepat, penyiar akan menggunakan model komunikasi mana yang akan digunakan pada saat siaran. model komunikasi terbagi menjadi 4. Model komunikasi satu arah yang berarti penyampaian pesan dari komunikator ke komikan menggunakan media tanpa adanya umpan balik dalam artian komikan hanya sebagai penerima pesan atau pendengar, Model komunikasi antar pribadi, komunikasi antara dua orang yang terjadi secara langsung berhadapan muka (face to face) atau melalui telpon, pesan singkat yang menggunakan suatu media, hal ini bersifat dua arah atau timbal balik. Model komunikasi kelompok, komunikator dan komunikan berada disuatu perkumpulan kelompok kecil atau kelomok besar mereka berdiskusi dan saling tukar pikiran. Model komunikasi massa, komunikasi menggunakan media modern, seperti surat kabar, siaran radio, siaran tv, dan film layar lebar yang ditunjukan pada khalayak luas.

Sebagai seorang penyiar radio pun harus memiliki karakteristik yang berbeda dengan penyiar lainnya, penyiar sebaiknya mampu menjadi dirinya sendiri, tidak menirukan karakter orang lain dan mengada-ngada dalam menjalankan tugasnya harus bersifat natural sehingga pada saat siaran benar-benar santai dan rileks. Sikap natural ini akan menjadi daya tarik tersendiri yang berpengaruh terhadap citra dimana seorang penyiar itu bertugas, sehingga karakteristik itu akan banyak digemari para pendengar.

Radio Dahlia adalah radio yang terkenal dan memiliki peringkat nomor satu di Kota Bandung. Karena selalu menyuguhkan program acara lagu-lagu dangdut, pop sunda dan melayu, penyiar radio dahlia pun memiliki karakter yang berbeda saat membawakan program acaranya masing-masing, hal tersebut yang membuat peneliti tertarik untuk meneliti radio dahlia dari segi gaya komunikasi penyiarnya.

Dalam penelitian ini memiliki dua rumusan masalah yang pertama bagaimana gaya bahasa penyiar bandar dangdut dalam mempertahankan eksistensi radio Dahlia? Yang kedua bagaimana karakteristik penyiar bandar dangdut dalam mempertahankan eksistensi radio Dahlia?. Dari rumusan tersebut memiliki tujuan penilitian yaitu untuk mengetahui gaya bahasa yang digunakan penyiar bandar dangdut dalam mempertahankan eksistensi radio Dahlia dan untuk mengetahui karakteristik yang dibawakan penyiar bandar dangdut dalam 
Jurnal Ilmu Komunikasi UHO : Jurnal Penelitian Kajian Ilmu Komunikasi dan Informasi.

Volume 6, No. 1, Januari 2021, hlm 98-111

mempertahankan eksistensi radio Dahlia. Manfaat teoritis dari penelitian ini diharpakan dapat menambah informasi dan pengetahuan bagi mahasiswa khususnya fakultas ilmu komunikasi (broadcasting). Dan penelitian ini dapat menjadi referensi bagi pihak yang membutuhkan penelitian yang sejenis terutama pihak akademik, manfaat praktis dari penelitian ini dapat membantu bagi perusahaan untuk menjadi evaluasi, acuan dan gambaran dalam mempertahankan eksistensi radio.

Menurut teori logika pesan, setiap orang dalam menyampaikan pesannya akan terkesan sama meskipun dalam situasi yang berbeda-beda, bahkan bentuk pesan tersebut akan bersifat sederhana saat pesan tersebut mempunyai bentuk dari penggunaan pesan tersebut. Namun ketika seseorang mempunyai banyak tujuan yang akan dicapai dengan segala potensinya, maka apapun logika yang digunakan dalam merancang pesan akan menghasilkan berbagai bentuk pesan yang berbeda.

Barbara $\mathrm{O}^{e c}$ Keefe dalam tesisnya menyatakan bahwa manusia memiliki kemampuan berpikir secara berbeda tentang bagaimana cara berkomunikasi dan merancang pesan, dan bagiamana manusia menggunakan logikanya yang berbeda-beda untuk memutuskan apa yang harus dikatakan kepada orang lain pada situasi tertentu. O'Keefe memperkenalkan istilah logika dalam merancang pesan (message design logic) yakni menjelaskan bagaimana suatu proses berpikir yang terjadi hingga munculnya pesan.

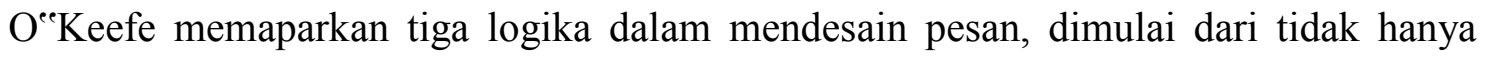
terpusat pada orang (least person-centered) hingga yang sangat terpusat (most personcentered). Logika ekspresif (expressive logic), yaitu logika yang melihat komunikasi sebagai cara dalam mengekspresikan diri dan untuk menyatakan perasaan dan pikiran. Pesan yang ada pada logika ekspresif ini sifatnya terbuka dan reaktif dan hanya fokus pada memberikan sedikit perhatian pada kebutuhan dan keinginan orang lain. Dalam hal ini, logika ekspresif bersifat self-centered atau terpusat pada diri si pembicara, kebalikan dari person-centered atau terpusat pada lawan bicara yang dikenal dalam teori konstruktivisme. Logika konvensional (conventional logic), yakni logika yang menjelaskan bahwa komunikasi sebagai suatu bentuk permainan yang dimainkan dengan mengikuti beberapa aturan. Logika ini bertujuan untuk mendesain pesan yang pantas, sopan, menurut dengan aturan yang seharusnya telah diketahui setiap orang. Logika retorika (rhetorical logic) yaitu logika yang melihat komunikasi adalah sebagai cara untuk mengganti aturan melalui negosiasi. Pesan yang didesain dengan menggunakan logika ini cenderung luntur dan fleksibel, mempunyai pemahaman dan terpusat pada lawan bicara. Pembicara yang menggunakan logika ini 
Jurnal Ilmu Komunikasi UHO : Jurnal Penelitian Kajian Ilmu Komunikasi dan Informasi.

Volume 6, No. 1, Januari 2021, hlm 98-111

cenderung untuk memframing ulang keadaan yang dihadapi dalam berbagai tujuan, termasuk persuasi dan kesopanan, dapat digabungkan dalam satu kesatuan yang bulat (Morissan, 2013).

\section{METODE PENELITIAN}

Dalam penelitian ini peneliti menggunakan metode penelitian kualitatif dengan studi deskriptif. Penelitian kualitatif merupakan penelitian yang menemukan dan memahami fenomena atau peristiwa dari sudut pandang partisipan, penelitian kualitatif secara umum dapat digunakan untuk meneliti tentang kehidupan masyarakat, sejarah, aktivitas sosial dan lainnya.

Metode deskriptif kualitatif bertujuan untuk mendeskripsikan relitas yang sedang terjadi secara sistematis, factual, dan akurat. Dengan konsep atau kerangka yang sudah dimiliki, harus dilakukan secara observasi agar dapat menghasilakan variabel beserta indikator yang dapat menggambarkan realitas tanpa menjelaskan hubungan antara variable (Sutopo, 2002). Untuk mendeskripsikan penelitian ini peneliti nantinya akan mencari data sebanyak mungkin melalui observasi, wawancara, dan dokumen yang sesuia dengan kebutuhan penilitian nantinya.

\section{HASIL DAN PEMBAHASAN}

Radio Dahlia adalah radio yang sudah mengudara sejak tahun 1970 dengan waktu siaran 24 jam non-stop. Awal terbentuknya Radio Dahlia yaitu pada tahun 1968, keluarga Ny. Siti Dahlia membuat sebuah usaha kecil yang diberi nama usahanya "Salon Dahlia". Salon Dahlia merupakan usaha jasa kecantikan. Dalam upaya meningkatkan usaha saja kecantikan tersebut pemilik usaha melakukan promosi dengan cara mendirikan pemancar amatiran yang diberi nama Radio Dahlia. Radio dahlia memiliki value yaitu kebutuhan dan keinginan pendengar merupakan aset terbesar yang menjadi acuan tujuan bisnis kami untuk selalu membuat program-program acara yang tepat guna (Rado Dahlia FM, n.d.). Radio Dahlia selalu melakukan inovasi di semua aspek management secara periodik agar tetap terdepan diantara radio yang ada di Kota Bandung. Dengan perkembangan teknologi informasi yang semakin cepat, yaitu teknologi industry 4.0, radio dahlia dapat diakses melalui media internet atau streaming. Dengan pengaplikasian radio streaming, kini radio dahlia dapat diakses tidak hanya di kota Bandung, tapi di seluruh dunia. Hal ini penting bagi perkembangan dan persaingan bisnis radio yang dipengaruhi oleh berbagai macam faktor, maka dari itu radio 
Jurnal Ilmu Komunikasi UHO : Jurnal Penelitian Kajian Ilmu Komunikasi dan Informasi.

Volume 6, No. 1, Januari 2021, hlm 98-111

dahlia tetap konsisten menyiarkan program siaran yang informatif, edukatif, menghibur dan menciptakan suasana positif bagi para pendengarnya. Radio dahlia eksis dikalangan masyarakat karena selalu menyiarkan musik dangdut, pop sunda dan melayu yang menjadi trend setter bagi pecinta musik dangdut di Kota Bandung dan sekitarnya. Berdasarkan hasil observasi yang telah dilakukan, hal tersebut di buktikan dengan adanya data yang di peroleh dari pihak Radio Dahlia yaitu :

Gambar data diatas menunjukan bahwa Radio Dahlia merupakan stasiun radio terkenal dan terdepan dengan peringkat nomor satu di Kota Bandung. Radio ini memiliki banyak pendengar dari semua kalangan masyarakat, karena Radio Dahlia selalu menyajikan program yang menarik untuk didengarkan. Keunggulan Radio Dahlia dibanding dengan radio lainnya, radio ini memiliki penyiar dengan ciri khas masing-masing di setiap program acaranya. Gaya komunikasi penyiar dalam meningkatkan minat pendengar yang selalu menyampaikan pesan

\begin{tabular}{|c|c|c|c|c|c|c|c|c|c|c|c|c|c|c|}
\hline Rank & Station & Sample & $\begin{array}{l}\text { Potential } \\
\text { (000's) }\end{array}$ & $\begin{array}{l}\text { Cume } \\
\text { (000's) }\end{array}$ & $\begin{array}{c}\text { Cume } \\
\%\end{array}$ & \begin{tabular}{|c|} 
Average \\
Audience \\
(OOO's)
\end{tabular} & $\begin{array}{l}\text { ExAud } \\
\text { (000's) }\end{array}$ & $\begin{array}{c}\text { Ex Aud } \\
\%\end{array}$ & T.S.L. & $\begin{array}{c}\text { Share } \\
\%\end{array}$ & $\begin{array}{c}\text { Tarp } \\
\%\end{array}$ & $\begin{array}{c}\text { Index } \\
\%\end{array}$ & $\begin{array}{c}\text { Profile } \\
\%\end{array}$ & $\begin{array}{c}\text { Share \% } \\
\text { (selected) }\end{array}$ \\
\hline 1 & DAHLIA & 1008 & 4228 & 1249 & 29.5 & 53 & 244 & 19.6 & 7.05 & 22.4 & 1.2 & 100 & 100 & 22.4 \\
\hline 2 & RAMA & 1008 & 4228 & 885 & 20.9 & 34 & 131 & 14.8 & 6.29 & 14.6 & 0.8 & 100 & 100 & 14.6 \\
\hline 3 & ARDAN & 1008 & 4228 & 754 & 17.8 & 22 & 215 & 28.5 & 4.59 & 9.5 & 0.5 & 100 & 100 & 9.5 \\
\hline 4 & CAKRA FM & 1008 & 4228 & 725 & 17.1 & 32 & 170 & 23.5 & 7.28 & 13.7 & 0.8 & 100 & 100 & 13.7 \\
\hline 5 & COSMO FM & 1008 & 4228 & 410 & Sun & bbers: R & adio I & Daftia & F $\mathrm{ma})$ & 6.7 & 0.4 & 100 & 100 & 6.7 \\
\hline 6 & MAYANADA & 1008 & 4228 & 305 & 7.2 & 9 & 3 & 1.1 & 5.05 & 3.9 & 0.2 & 100 & 100 & 3.9 \\
\hline 7 & GARUDA & 1008 & 4228 & 214 & 5.1 & 6 & 7 & 3.1 & 4.47 & 2.6 & 0.1 & 100 & 100 & 2.6 \\
\hline 8 & SHINTA & 1008 & 4228 & 209 & 4.9 & 7 & 12 & 5.7 & 5.3 & 2.9 & 0.2 & 100 & 100 & 2.9 \\
\hline 9 & I-RADIO & 1008 & 4228 & 143 & 3.4 & 4 & 5 & 3.5 & 4.31 & 1.6 & 0.1 & 100 & 100 & 1.6 \\
\hline 10 & PARAMUDA & 1008 & 4228 & 136 & 3.2 & 5 & 20 & 15 & 6.34 & 2.3 & 0.1 & 100 & 100 & 2.3 \\
\hline 11 & MOFM & 1008 & 4228 & 134 & 3.2 & 5 & 25 & 19 & 7.12 & 2.4 & 0.1 & 100 & 100 & 2.4 \\
\hline 12 & URBAN FM & 1008 & 4228 & 130 & 3.1 & 3 & 7 & 5.5 & 3.5 & 1.3 & 0.1 & 100 & 100 & 1.3 \\
\hline 13 & BANDUNG FM & 1008 & 4228 & 126 & 3 & 2 & 0 & 0 & 2.32 & 0.8 & 0 & 100 & 100 & 0.8 \\
\hline 14 & RAKA & 1008 & 4228 & 117 & 2.8 & 3 & 10 & 9 & 3.49 & 1.1 & 0.1 & 100 & 100 & 1.1 \\
\hline 15 & MARA & 1008 & 4228 & 96 & 2.3 & 1 & 0 & 0 & 2.11 & 0.5 & 0 & 100 & 100 & 0.5 \\
\hline 16 & DELTA FM & 1008 & 4228 & 82 & 1.9 & 3 & 0 & 0 & 5.26 & 1.1 & 0.1 & 100 & 100 & 1.1 \\
\hline 17 & PR FM & 1008 & 4228 & 71 & 1.7 & 2 & 6 & 8.7 & 4.27 & 0.8 & 0 & 100 & 100 & 0.8 \\
\hline 18 & oz & 1008 & 4228 & 67 & 1.6 & 2 & 4 & 5.6 & 4.27 & 0.8 & 0 & 100 & 100 & 0.8 \\
\hline 19 & ELSHINTA & 1008 & 4228 & 63 & 1.5 & 3 & 5 & 8.5 & 7.09 & 1.1 & 0.1 & 100 & 100 & 1.1 \\
\hline 20 & HITS FM & 1008 & 4228 & 58 & 1.4 & 1 & 0 & 0 & 3.37 & 0.5 & 0 & 100 & 100 & 0.5 \\
\hline 21 & PRAMBORS & 1008 & 4228 & 55 & 1.3 & 1 & 5 & 9.5 & 3.19 & 0.5 & 0 & 100 & 100 & 0.5 \\
\hline 22 & 99ERS & 1008 & 4228 & 51 & 1.2 & 1 & 7 & 13.5 & 3.44 & 0.5 & 0 & 100 & 100 & 0.5 \\
\hline 23 & MGT & 1008 & 4228 & 41 & 1 & 1 & o & 0 & 3.35 & 0.4 & 0 & 100 & 100 & 0.4 \\
\hline & Total & 1008 & 4228 & 2733 & 64.6 & 235 & 0 & 0 & 14.25 & 100 & 5.5 & 100 & 100 & 100 \\
\hline
\end{tabular}

komunikasi bersifat informatif, persuasif, dan instruktif dimaksudkan untuk memberikan pemahaman kepada pendengarnya dan menarik minat pendengar. Penyiar radio adalah komunikator dalam proses komunikasi. Penyiar radio adalah pengirim pesan untuk khalayaknya, Gaya komunikasi penyiar menjadi salah satu kunci utama dalam mempertahankan eksistensi stasiun radio melalui program-program yang dipandunya. Sehingga radio dahlia membuat program unggulannya yaitu Bandar Dangdut. Program acara Bandar Dangdut tersebut begitu banyak diminati terutama ibu-ibu rumah tangga, karena 
Jurnal Ilmu Komunikasi UHO : Jurnal Penelitian Kajian Ilmu Komunikasi dan Informasi.

Volume 6, No. 1, Januari 2021, hlm 98-111

menurut para pendengar acara musik dangdut atau pop sunda ini begitu menghibur dan bisa menemani aktivitas sehari-hari.

Berdasarkan hasil data wawancara diketahui bahwa kemampuan komunikasi penyiar pada Program Bandar Dangdut sangat berpengaruh besar terhadap pendengar. Program Bandar Dangdut ini sudah mengudara selama 18 tahun sejak tahun 2002 samapi saat ini yang disiarkan setiap hari dari pukul 08.00-10.00 WIB. Program Bandar Dangdut ini dipandu oleh 2 orang penyiar dengan gaya komunikasi dan cara penyampaian informasi sangat berbedabeda. Oleh karena itu, program siaran radio harus memperhatikan teknik penyiaran yang baik. Peran penyiar disini tidak hanya untuk membuat siaran yang baik, tapi juga menarik pendengar.

Salah satu penyiar bandar dangdut dalam mempertahankan eksistensi radio Dahlia pun memiliki ciri khas. "Yang sering disebut Neng Bandar Mia sudah bergabung dengan program acara bandar dangdut selama 18 tahun memiliki karakteristik yang berebeda dengan yang lainnya dengan pembawaan gaya nge-rap saat siaran, karakter seperti ini dari dulu hingga saat ini masih tetap konsisten digunakan sehingga program acara bandar dangdut tetap eksis di radio dahlia”. Memiliki karakteristik yang berbeda dengan penyiar radio lainnya menjadi daya tarik untuk para pendengar agar tetap setia. Menurut hasil data yang diperoleh bahwa hasil wawancara yang kalimatnya dikembangkan ini masuk pada teori logika pesan yang dirancang pada logika ekspresif (expressive logic).

Dari hasil riset tersebut, dapat diketahui bahwa karakteristik penyiar Bandar Dangdut memiliki ciri khas yang berbeda dengan penyiar lainnya, karakteristik ini dominan menggunakan logika ekspresif pada teori logika pesan karena memiliki karakteristik yang berbeda dengan penyiar radio lainnya menjadi daya tarik untuk para pendengar agar tetap setia dan dapan mempertahankan eksistensi radio Dahlia FM.

Untuk menarik banyak pendengar dan bersaing dengan radio-radio lainnya yang ada di Bandung, Radio Dahlia khusunya program Bandar Dangdut harus memiliki daya tarik tersendiri pada acara siaran. Bukan dari segi karakteristik seorang penyiar saja tapi dari bahasa dan gaya komunikasi penyiar tentunya merupakan hal penting yang harus diperhatikan oleh seorang penyiar dalam menyampaikan informasi. Dalam melakukan siaran, sebaiknya seorang penyiar menggunakan bahasa yang dapat dimengerti pendengar dan diterima, serta dilengkapi dengan gaya komunikasi yang dapat menarik minat dengar masyarakat, 
Jurnal Ilmu Komunikasi UHO : Jurnal Penelitian Kajian Ilmu Komunikasi dan Informasi.

Volume 6, No. 1, Januari 2021, hlm 98-111

Gaya bahasa yang digunakan penyiar bandar dangdut dalam mempertahankan eksistensi Radio Dahlia, yaitu "Neng bandar mia biasanya mengunakan bahasa kesaharian atau bahasa sunda, karena Radio yang berlokasi di Bandung rata-rata masyarakatnya mengunakan bahasa sunda, untuk merangkul dan lebih dekat dengan para pendengarnya bahasa-bahasa ringan dan tetap sopan yang terpenting gaya bahasa harus dapat dimengerti dan diterima oleh pendengar". Menurut hasil data yang diperoleh bahwa hasil wawancara yang kalimatnya dikembangkan ini masuk pada teori logika pesan yang dirancang pada Logika konvensional (conventional logic).

Dari hasil riset tersebut, dapat diketahui bahwa gaya bahasa penyiar Neng Bandar pada saat membawakan acara Bandar Dangdut lebih dominan menggunakan logika konvensional pada teori logika pesan karena ia melakukan penyesuaian diri ketika berhadapan dengan pendengarnya, terutama dari segi penggunaan bahasa, bahasa yang digunakan lebih sederhana dan tidak formal agar dimengerti dan diterima pendengar.

Selain itu, Gaya bahasa atau pesan yang disampaikan seorang penyiar harus bisa mempengaruhi pola pikir pendengar mengenai informasi, hiburan atau apapun yang disampaikan harus mengikuti trend pasar, menurut "neng bandar mia tidak memiliki tema wajib pada saat siaran tetapi mengalir begitu saja, hal yang wajib diselingi pada saat siaran harus membawakan pantun dan tatarucingan (tekateki), agar program bandar dangdut tetap diterima oleh banyak segmen”. Segmentasi tersebut yang membedakan radio dahlia dengan radio-radio lainnya. Menurut hasil data yang diperoleh bahwa hasil wawancara yang kalimatnya dikembangkan ini masuk pada teori logika pesan yang dirancang pada Logika Retorika (rhetorical logic).

Dari hasil riset untuk program acara Bandar Dangdut penyiar tidak ada materi atau tema khusus yang disampaikan, penyiar hanya secara spontan saja menyampaikan isi siarannya, yang terpenting informasi, hiburan atau apapun yang disampaikan dan gaya bahasa penyiar dapat mempengaruhi pola pikir pendengar. Hal ini lebih dominan mengunakan logika retorika pada teori logika pesan karena gaya bahasa atau informasi yang disampaikan dapat mempengaruhi pola pikir pendengar, sehingga akan terciptanya suasana positif bagi para pendengarnya.

\section{SIMPULAN}

Perkembangan industri 4.0 pada dunia radio sangat berpengaruh dalam berbagai aspeknya. Hal yang paling berpengaruh pada radio dalam industri 4.0 adalah dari segi 
Jurnal Ilmu Komunikasi UHO : Jurnal Penelitian Kajian Ilmu Komunikasi dan Informasi.

Volume 6, No. 1, Januari 2021, hlm 98-111

teknologi radio frekuensi dari gelombang radio elektromagnetik ke jaringan digital internet (streaming), sehingga radio dahlia dapat diakses dari segala penjuru dunia, tidak hanya di kota Bandung. Masyarakat penyuka dangdut di luar negeri atau masyarakat indonesia yang ada diluar negeri kini dengan mudah dapat mengaksesnya. Selain mengaplikasikan teknologi digital, radio juga dipengaruhi oleh gaya komunikasi penyiarnya itu sendiri.

Gaya komunikasi penyiar bandar dangdut dalam mempertahankan eksistensi radio dahlia memiliki ciri khas yang berbeda dengan radio lainnya, mereka memiliki karakter masing-masing yang sangat natural tercipta dari dirinya sendiri, salah satu penyiar bandar dangdut memiliki karakter dengan gaya nge-rap pada saat siaran, penyiar juga menyesuaikan dengan bahasa yang digunakan pendengar, biasanya bahasa keseharian atau bahasa sunda agar dapat dipahami oleh para pendengarnya, komunikasi antara penyiar dan pendengar pun akan berjalan dengan baik.

Pada program acara bandar dangdut ini, tidak ada tema yang di angkat namun mengalir begitu saja tetapi wajib membawakan pantun dan tatarucingan pada saat siaran, masalah yang dibahas tidak jauh dari kehidupan sehari-hari, sehingga ketika penyiar membawakan acara suasana menjadi hangat dan akrab karena pendengar yakin bahwa ada orang lain yang pernah memiliki permasalahan yang sama. Penyiar pun memutarkan lagu-lagu yang direquest oleh para pendengarnya karena dengan tujuan memuturkan agar dapat membantu mood mereka menjadi lebih baik, cara penyiar tersebut tentu sangat berpengaruh untuk menumbuhkan minat pendengar untuk mendengarkan acara tersebut.

Penyiar agar membuat para pendengar terkesan dan selalu ingat dengan acara bandar dangdut, penyiar memberikan pantun dan tatarucingan (teka-teki), karena penyiar berusaha memecahkan suasana menyenangkan untuk bahan pembahasan yang menarik dan membuat para pendengarnya terkesan. Selain dengan pantun dan tatarucingan (teka-teki) penyiar selalu memberikan kesempatan bagi para pendengar untuk reques lagu dan menyampaikan salam untuk keluarga atau orang yang ditujun hal ini membuat para pendengar menarik untuk selalu mendengarkan acara tersebut. 
Jurnal Ilmu Komunikasi UHO : Jurnal Penelitian Kajian Ilmu Komunikasi dan Informasi.

Volume 6, No. 1, Januari 2021, hlm 98-111

\section{DAFTAR PUSTAKA}

Morissan. (2013). Teori Komunikasi Individual Hingga Massa. Prenadamedia Group.

Rado Dahlia FM. (n.d.). History. Retrieved June 20, 2020, from www.radiodahlifm.com

Sutopo. (2002). Metodologi Penelitian Kualitatif. Sebelas Maret University Press.

Tiartanto, ius yudo. (2010). Broadcasting Radio : anduan Teori dan Praktek. Pustaka Book.

Moleong, Lexy J. (2007) Metodologi Penelitian Kualitatif, Penerbit PT Remaja Rosdakarya Offset, Bandung

Emadwiandr. (2013). STRATEGI KOMUNIKASI PENYIAR RADIO DAKWAH MU'ADZ BIN JABAL DALAM MENINGKATKAN MINAT PENDENGAR. Journal of Chemical Information and Modeling, 53(9), 1689-1699. https://doi.org/10.1017/CBO9781107415324.004

Puji, A. (n.d.). Eksistensi dan Gaya Kepemimpinan Radio Lokal. 105-114. 